\title{
DESAIN MOTIF BATIK TEBO DI KECAMATAN TEBO TENGAH KABUPATEN TEBO PROVINSI JAMBI
}

\author{
Nopri Yulia ${ }^{1^{*}}$, Weni Nelmira ${ }^{2^{*}}$ \\ Program Studi Pendidikan Kesejahteraan Keluarga Jurusan Ilmu Kesejahteraan Keluarga \\ Fakultas Pariwisata dan Perhotelan \\ Universitas Negeri Padang \\ Jl. Prof. Dr. Hamta, Air Tawar Padang, Kel. Air Tawar Barat, Kec. Padang Utara, Kota Padang, Kode Pos 25171 \\ Sumatera Barat. Indonesia \\ Email: novriyulia073@gmail.com
}

\begin{abstract}
Abstrak
Masalah dalam penelitian ini yaitu masyarakat Kabupaten Tebo selama ini hanya mampu menikmati batik secara fungsional saja tanpa mengetahui nama dari bentuk motif apalagi makna filosofis yang terkandung. Penelitian ini bertujuan untuk mendeskripsikan desain motif yang meliputi motif utama, motif pelengkap, dan isen-isen. Metode penelitian ini menggunakan metode deskriptif kualitatif. Jenis data berupa data primer dan data sekunder. Teknik pengumpulan data melalui observasi, wawancara, dan dokumentasi. Teknik analisa data dilakukan dengan teknik analisis model interaktif. Hasil penelitian menunjukkan bahwa motif yang terdapat pada Rumah Batik Tebo terdiri dari 12 motif yaitu motif tanggo rajo, simpang tugu, bambu runcing, rebung nyengum, rumah adat, bungo pakis, konde mina, tapak kudo, bungo tanjung, baibat, tapak kudo dan buah daun sawit dan pawn.
\end{abstract}

Kata Kunci: modul, media pembelajaran, teknologi, busana.

\begin{abstract}
The problem in this study is that the people of Tebo Regency have only been able to enjoy batik functionally without knowing the names of the motifs especially the philosophical meanings contained. This study aims to describe the motive design which includes the main motives, complementary motifs, and isen-isen. This research method uses a qualitative descriptive method. Types of data in the form of primary data and secondary data. Collecting data trough obsevation, interviews, and documentation. Data analysis techniques are carried out by interactive model analysis techniques. The results showed that the motifs found in Rumah Batik Tebo consisted of 12 motifs, namely motifs tanggo rajo, simpang tugu, bambu runcing, rebung nyengum, rumah adat, bungo pakis, konde mina, tapak kudo, bungo tanjung, baibat, tapak kudo dan buah daun sawit dan pawn.
\end{abstract}

Keywords: design, motif batik, batik tebo.

\section{PENDAHULUAN}

Batik tidak hanya sekedar kain yang bermotif dan berwarna yang khas, tetapi lebih dari itu, bentuk, fungsi dan maknanya mempunyai karakteristik tersendiri. Ragam hias dan pewarnaan yang dituangkan pada batik ini merupakan refleksi estetis dan budaya masyarakat Kabupate Tebo. Motifmotifnya diambil dari bentuk kebudayaan dan lingkungan masyarakat yang mengungkapkan bahwa adat dan budaya Kabupaten Tebo yang masih kental. Batik Tebo menyimpan konsep artistik yang yidak dibuat semata-mata untuk keindahan, indahnya bukan hanya sekedar pemuas mata, tetapi juga mempunyai nilai fungsional sebagai produk baju, kain sarung, sajadah, dompet, lacak (ikat kepala khas budaya melayu Jambi, yang biasa digunakan oleh kaum pria), selendang, syal, tatakan gelas, kipas dan kalung. Selain mempunyai nilai fungsional, motif dalam batik ini juga mempunyai makna, akan tetapi tidak semua masyarakat menyadari keistimewaan tersebut. Maknamakna tersebut menunjukkan kedalaman pemahaman terhadap nilai-nilai lokal dan sampai sekarang nilanilai tersebut masih bertahan.

Berdasarkan data dari Dinas Koperasi Industri dan Perdagangan (KOPERINDAG) Kabupaten Tebo tanggal 18 Oktober 2018 Kabupaten Tebo memiliki 6 industri kecil menengah yang tersebar dibeberapa daerah di Kabupaten, antara lain Sanggar Mursida, Sanggar Batik Bungo Tanjung, Sanggar Usaha Mandiri Citra Zhipawah, Sanggar Sma Lima, Sanggar Risnu, dan Sanggar Rumah Batik Tebo.

Rumah Batik Tebo memiliki karakteristik unik, diantaranya dalam segi motif, dan warna batik Tebo memiliki kekhasan tersendiri dibanding batik daerah 


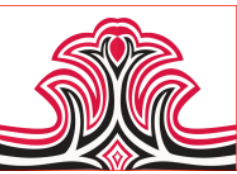

lainnya. Herry (2013 : 53) "Warna dalam batik terbagi menjadi dua yaitu warna alam dan warna sintetis. Warna alam diperoleh baik berasal dari hewan (lacdyes) ataupun berasal dari tumbuhan seperti akar, batang, daun, buah, kulit dan bunga". Cara pemberian warna juga beragam.

Ramanto (1980 : 64) "Dalam pembatikan dikenal dua cara pemeberian warna yaitu dengan mencelup dan mencolet, mencelup yaitu mewarnai seluruh mori yang sudah diberi lilin sedangkan mencolet adalah mewarnai bagian tertentu saja dengan cara menguaskan bahan warna pada bidang-bidang yang diwarnai itu". Tujuan dari penelitian ini adalah untuk mendeskripsikan tentang desain motif batik Tebo yang meliputi motif utama, motif pelengkap, dan isen-isen di Rumah Batik Tebo Kecamatan Tebo Tengah Kabupaten Tebo Provinsi Jambi. Tujuan dari penelitian ini adalah untuk mendeskripsikan desain motif batik Tebo yang meliputi motif utama, motif pelengkap dan isen-isen.

\section{KAJIAN TEORI}

Ernawati (2008 : 387) "Bentuk dasar motif dan ragam hias dapat dikelompokkan menjadi tiga kelompok besar yaitu bentuk naturalis, bentuk geometris, dan bentuk dekoratif. Bentuk naturalis, bentuk naturalis yaitu bentuk yang dibuat berdasarkan bentuk tumbuhtumbuhan yang ada di alam sekitar seperti bentuk tumbuh-tumbuhan, bentuk hewan atau binatang, bentuk batu-batuan, bentuk awan, bentuk matahari, bintang, bnetuk pemandangan lama dan lain-lain. Bentuk geometris, bentuk geometris yaitu bentukbentuk yang mempunyai bentuk teratur dan dapat diukur menggunakan alat ukur. Contohnya bentuk segi empat, segitiga, lingkaran, kerucut, silinder dan lainlain. Bentuk dekoratif merupkan bentuk yang berasal dari bentuk naturalis dan bentuk geometris yang sudah distilasi atau direngga sehingga muncul bentuk baru tetapi cir khas bentuk tersebut masih terlihat. Bentukbentuk ini sering digunakan untuk membuat hiasan pada benda baik pada benda-benda keperluan rumah tangga maupun hiasan pada busana.

Mila (2010 : 13) "Motif banyak dipengaruhi oleh berbagai faktor yaitu ragam hias batik pada umumnya dipengaruhi dan erat kaitannya dengan faktor-faktor lainnya yaitu letak geografis daerah pembuatan batik bersangkutan, sifat dan tata penghidupan daerah yang bersangkutan, kepercayaan dan adat istiadat yang ada di daerah yang bersangkutan, keadaan alam sekitarnya termasuk flora dan faunanya, adanya kontak atau hubungan antara daerah pembatikan”. Motif batik
Gorga Jurnal Seni Rupa

Volume 08 Nomor 01 Januari-Juni 2019

p-ISSN: 2301-5942 | e-ISSN: 2580-2380

tidak saja dipengaruhi dari bakat atau seni yang ada pada diri orang yang membuatnya, akan tetapi banyak faktor-faktor yang mempengaruhi terciptanya motif batik tersebut.

Kusrianto (2013 : 5) "Batik memiliki dua unsur yaitu : ornamen motif batik dan isen-isen motif batik. Ornamen motif batik terdiri atas ornamen utama dan ornamen pengisi bidang, yaitu :

\section{Ornamen}

Ornamen adalah unsur dari motif, berupa bentuk gambar atau lukisan yang menghiasi kain batik. Dengan kata lain, motif batik terdiri atas susunan ornamen. Ornamen disebut juga ragam hias. Ada dua macam ornamen yaitu ornamen pokok atau utama dan ornamen pelengkap atau pengisi bidang.

\section{1).Ornamen Pokok}

Ornamen pokok atau ornamen utama berbentuk stilasi dari benda alam atau hewan, melambangkan suatu makna, mempunyai arti filosofis seperti ornamen meru, pohon ayat, ular atau naga, lidah api dan sebagainya. Biasanya berukuran cukup besar atau dominan dalam sebuah motif.

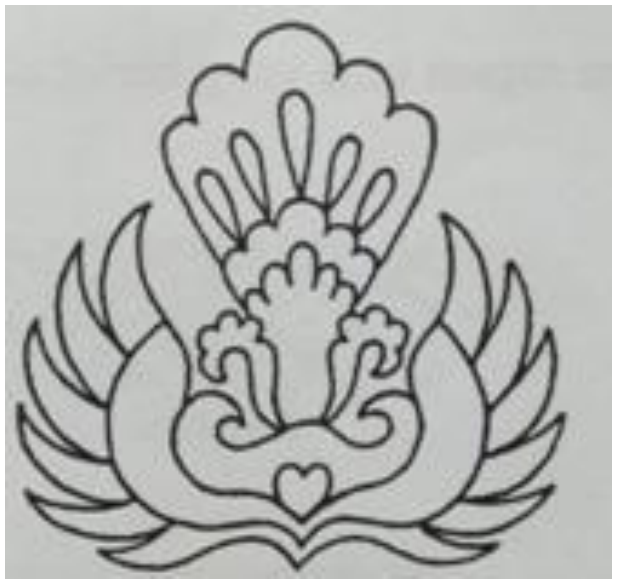

Gambar 1. Ornamen Utama (Sumber: Kusrianto, 2013:16)

\section{2).Ornamen Pelengkap}

Ornamen pelengkap atau pengisi bidang adalah ornamen yang dibuat untuk mengisi bidang yang kosong di samping ornamen pokok. Ornamen pelengkap tidak mempunyai arti atau makna tertentu kecuali untuk melengkapi hiasan dan keindahan. Misalnya ornamen tumbuhan seperti pohon, bunga, daun, dan hewan seperti burung, kupu-kupu, ikan, merak, ayam, dan sebagainya. 

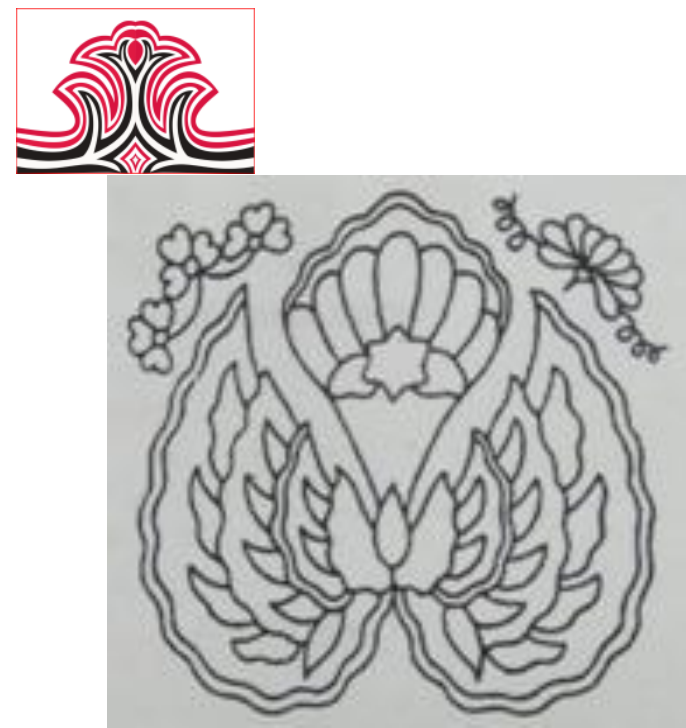

Gambar 2. Ornamen Pelengkap (Sumber: Kusrianto, 2013: 16)

\section{Isen}

Isen (isian) yaitu motif pengisi sebagai unsur pelengkap dalam motif batik. Isen merupakan pemanis dalam keseluruhan motif. Pada umunya isen berukuran kecil dan kadang rumit, dapat berupa titiktitik, garis-garis ataupun gabungan keduanya. Jumlah isen-isen banyak sekali, tetapi hanya beberapa saja yang masih banyak dijumpai dalam ragam hias yang berkembang sampai saat ini, antara lain:

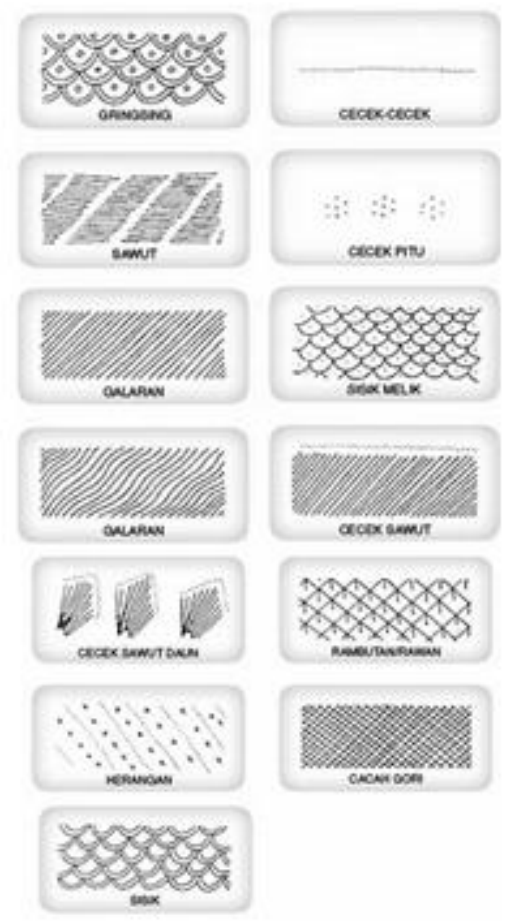

Gambar 3. Macam-Macam Isen (Sumber: Kusrianto, 2013: 28)

\section{METODE PENELITIAN}

Jenis penelitian ini adalah penelitian deskriptif dengan pendekatan kualitatif. Penelitian ini dilaksanakan di Rumah Batik Tebo. Jenis data yang digunakan yaitu data primer dan data sekunder dengan informan (untuk
Gorga Jurnal Seni Rupa

Volume 08 Nomor 01 Januari-Juni 2019

p-ISSN: 2301-5942 | e-ISSN: 2580-2380

diwawancarai) yaitu pimpinan/pengusaha dan pengrajin batik di Rumah Batik Tebo. Teknik pengumpulan data pada penelitian ini menggunakan tiga teknik yaitu teknik observasi, wawancara dan dokumentasi.

Teknik analisa data sesuai dengan pengolahan data yang bersifat deskriptif. Aktivitas dalam analisa data yaitu reduksi data, penyajian data dan penarikan kesimpulan dengan demikian dapat disimpulkan cara menganalisa data sebagai berikut, selama proses pengumpulan data, dilakukan reduksi data berarti merangkum, memilih hal-hal pokok, memfokuskan pada hal-hal penting. Dengan demikian kata yang telah direduksi akan memberikan gambaran yang lebih jelas dan mempermudah penelitian untuk melakukan pengumpulan data selanjutnya, penyajian data dapat dilakukan dalam bentuk uraian singkat dengan hubungan antara kategori dan sejenisnya. Dengan penyajian data maka akan mempermudah untuk memahami apa yang telah dipahami, kesimpulan dalam penelitian kualitatif merupakan temuan baru, temuan dapat berupa deskripsi atau gambaran suatu objek yang sebelumnya masih kurang jelas dan setelah diteliti menjadi jelas.

\section{HASIL DAN PEMBAHASAN \\ 1.Hasil \\ 1).Motif Utama}

Ragam hias yang dituangkan pada pada batik ini merupakan refleksi estetis dan kebuadayaan masyarakat tebo. Motif-motif diambil dari bentuk kebudayaan dan lingkungan masyarakat yang mengungkapkan bahwa adat dan budaya Tebo yang masih kental. Motif yang dihasilkan dari Rumah Batik Tebo yaitu motif-motif yang terinspirasi dari keadaan alam dan budaya lokal yang ada di Kabupaten Tebo. Motif batik di Rumah Batik Tebo adalah sebagai berikut: 

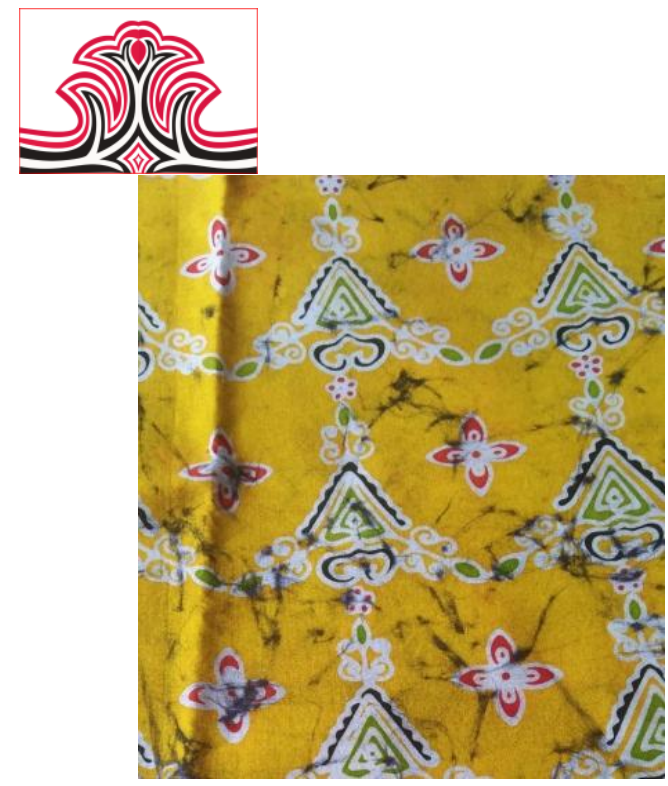

Gambar 4. Motif Tanggo Rajo

(Sumber: Nopri Yulia, 2018)

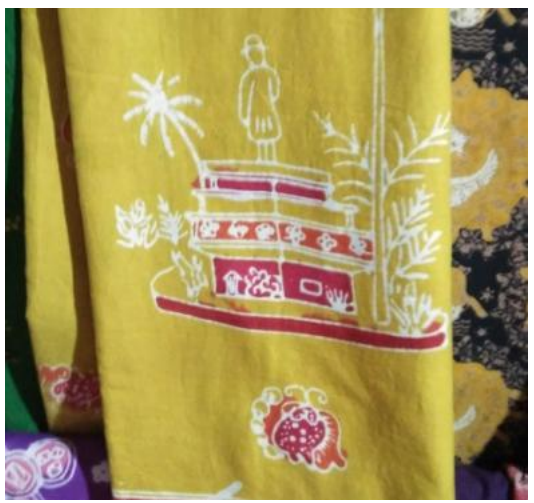

Gambar 5. Motif Simpang Tugu

(Sumber: Nopri Yulia, 2018)

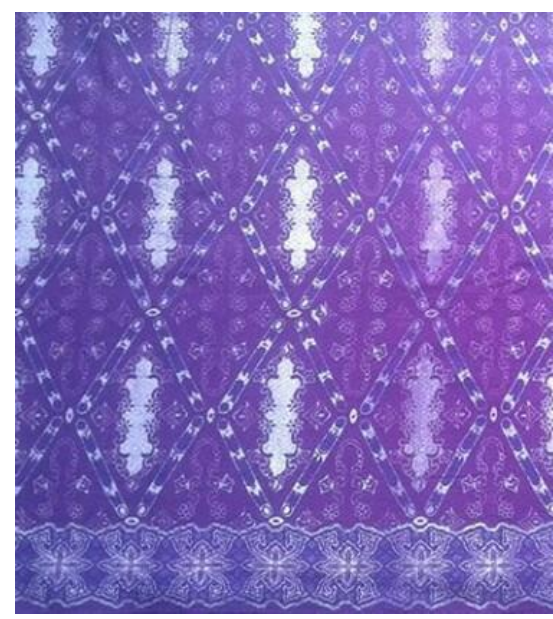

Gambar 6. Motif Bambu Runcing (Sumber: Koleksi Rumah Batik Tebo, 2018)
Gorga Jurnal Seni Rupa

Volume 08 Nomor 01 Januari-Juni 2019

p-ISSN: 2301-5942 | e-ISSN: 2580-2380

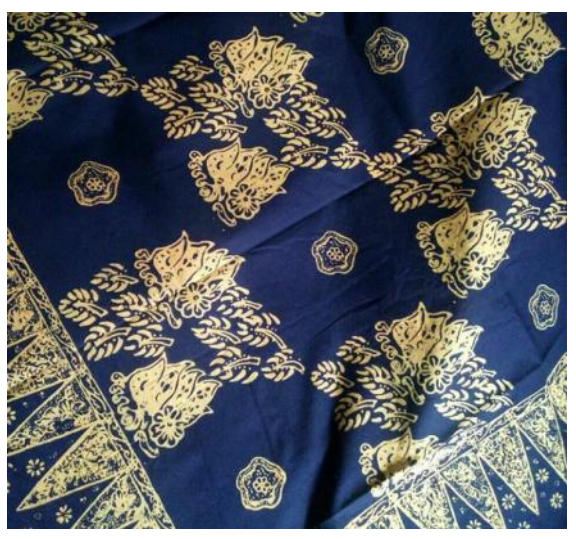

Gambar 7. Motif Rebung Nyengum (Sumber: Koleksi Rumah Batik Tebo, 2018)

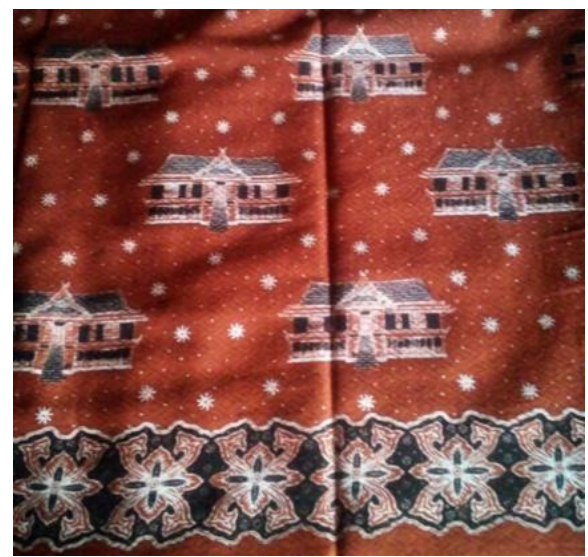

Gambar 8. Motif Rumah Adat

(Sumber: Koleksi Rumah Batik Tebo, 2018)

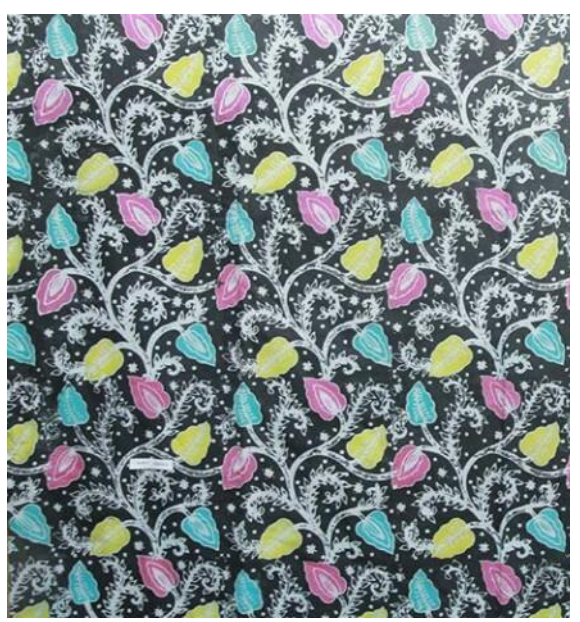

Gambar 9. Motif Bungo Pakis

(Sumber : Koleksi Rumah Batik Tebo, 2018) 


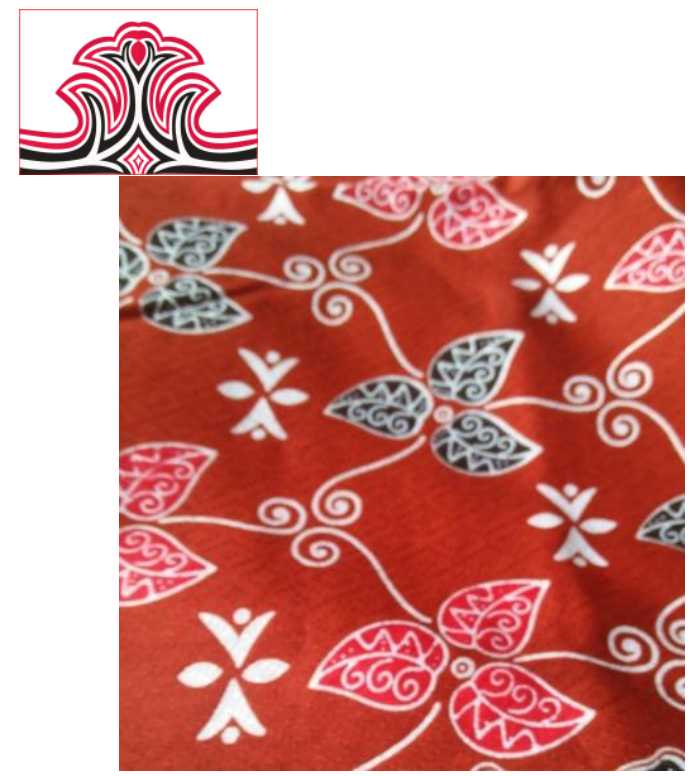

Gambar 10. Motif Konde Mina

(Sumber: Koleksi Rumah Batik Tebo, 2018)

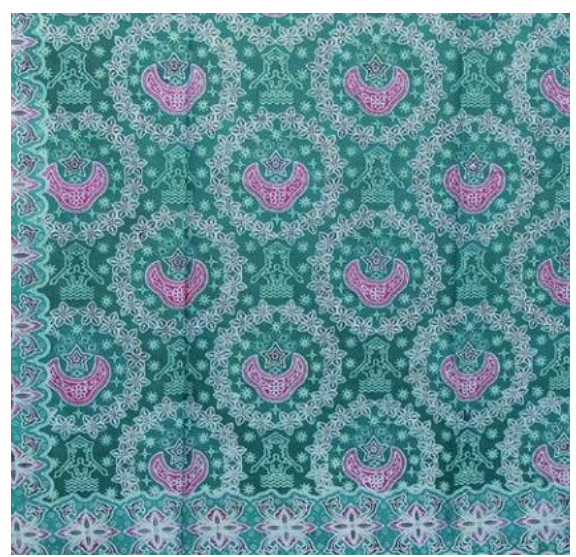

Gambar 11. Motif Tapak Kudo

(Sumber: Koleksi Rumah Batik Tebo, 2018)

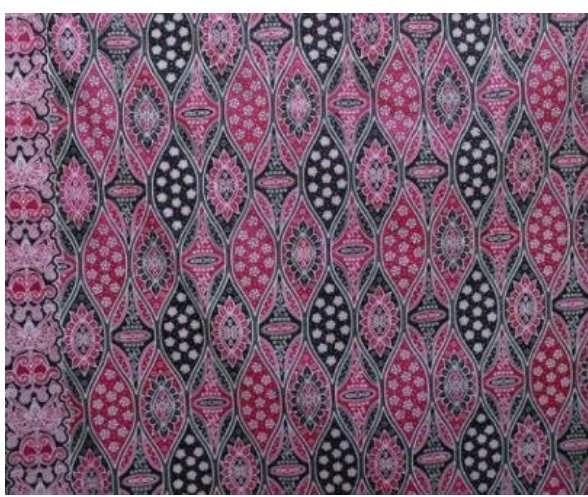

Gambar 12. Motif Bungo Tanjung

(Sumber: Koleksi Rumah Batik Tebo, 2018)
Gorga Jurnal Seni Rupa

Volume 08 Nomor 01 Januari-Juni 2019 p-ISSN: 2301-5942 | e-ISSN: 2580-2380

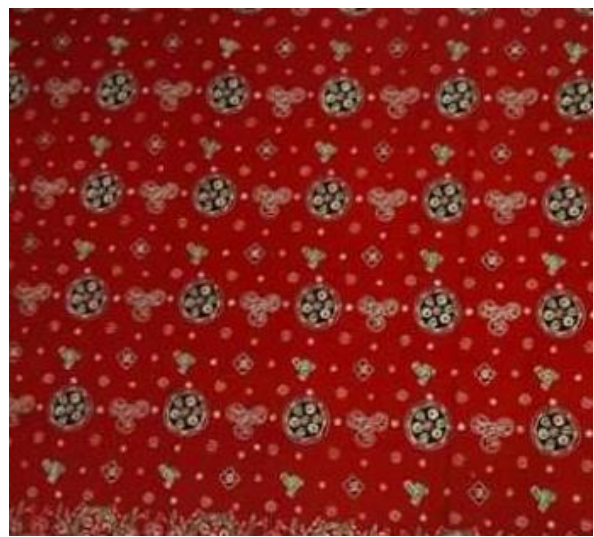

Gambar 13. Motif Baibat

(Sumber: Koleksi Rumah Batik Tebo, 2018)

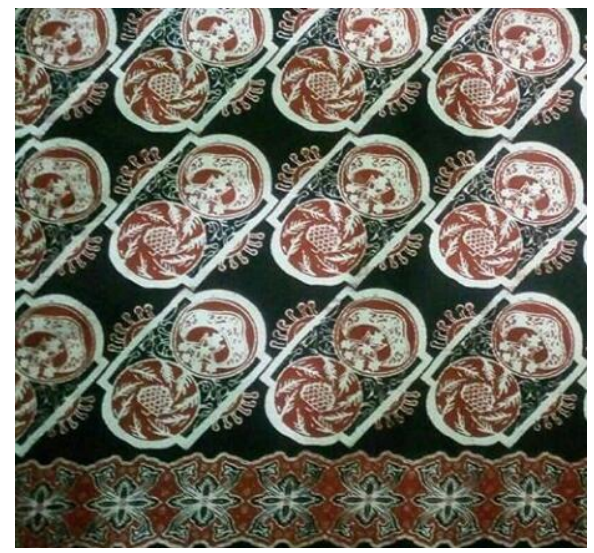

Gambar 14. Motif Tapak Kudo, Buah, dan Daun Sawit (Sumber: Koleksi Rumah Batik Tebo, 2018)

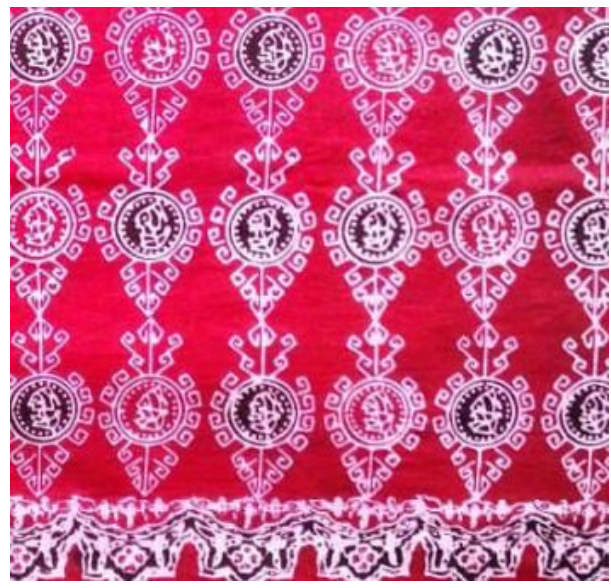

Gambar 15. Motif Pawn

(Sumber: Koleksi Rumah Batik Tebo, 2018)

Ornamen motif batik terdiri dari ornamen utama dan ornamen pelengkap serta isen-isen motif batik. Ornamen utama pada motif batik Tebo yaitu bunga pakis, buah sawit, daun sawit, bambu, koin, tusuk konde, tapak kuda, serta bangunan. 


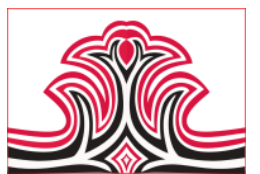

2).Ornamen Pelengkap

Ornamen pelengkap yaitu kupu-kupu, bunga, daun dan pohon.

\section{3).Isen-Isen}

Isen motif batik berfungsi sebagai pengisi bidang kosong pada kerangka ornamen sehingga menjadi ornamen yang sempurna. Isen-isen yaitu cecek-cecek, cecek pitu, kembang tampuk manggis dan ukel.

\section{Pembahasan}

Motif-motif yang tercipta tak luput dari pandangan alam dan kebudayaan sekitar, motif yang terinpirasi dari kekayaan kebudayaan tebo seperti motif tanggo rajo, simpang tugu, rumah adat, tapak kudo, konde mina, baibat dan pawn. Sedangkanan yang terinspirasi dari alam seperti bambu runcing, rebung nyengum, bungo pakis, bungo tanjung, motif kombinasi alam kebudayaan seperti motif tapak kudo, buah dan daun sawit.

\section{KESIMPULA DAN SARAN}

\section{Kesimpulan}

Motif batik di Rumah Batik Tebo terinspirasi dari keadaan alam dan kebudayaan masyarakat Tebo, adapun nama-nama batik di Rumah Batik Tebo yaitu motif tanggo rajo, simpang tugu, bambu runcing, rebung nyengum, rumah adat, bungo pakis, konde mina, tapak kudo, bungo tanjung, baibat, tapak kudo buah dan daun sawit dan pawn. Ornamen utama atau motif utama yaitu bunga pakis, buah sawit, daun sawit, bambu, tusuk konde, tapak kuda dan bangunan. Ornamen pelengkap terdiri dari kupu-kupu, bunga,daun, dan pohon. Dan isen-isen yaitu cecekcecek, cecek pitu, kembang tampuk manggis dan ukel

\section{Saran}

Berdasarkan hasil penelitian dan kesimpulan, maka peneliti menyampaikan beberapa saran sebagai berikut: Diharapkan Rumah Batik Tebo lebih mengembangkan atau mengkombinasikan batik dengan sepatu atau tas, kepada pihak pemerintah perlu memberi perhatian khusus tentang motif tebo sebagai salah satu aset kebudayaan yang harus tetap dipertahankan dan dikembangkan pada saat ini, dan agar penelitian ini tidak sampai disini saja, diharapkan adanya penelitian lanjutan lagi agar seni budaya itu sendiri semakin disukai dan minati untuk dikembangkan.

\section{DAFTAR RUJUKAN}

Ernawati, dkk. (2008). Tata Busana. Departemen Pendidikan dan Kebudayaan Direktorat Pendidikan Menengah Kejuruan. Padang.
Gorga Jurnal Seni Rupa

Volume 08 Nomor 01 Januari-Juni 2019

p-ISSN: 2301-5942 | e-ISSN: 2580-2380

Herry, Lisbijanto. (2013). Batik. Jakarta: Graha Ilmu. Kusrianto, A. (2013). Batik, Filosofi, Motif \& Kegunaan. Yogyakarta: Andi Offset

Mila, Karmila. (2010). Ragam Hias Tradisional Nusantara. Jakarta: Bee Media Indonesia.

Ramanto, Muzni. (1980). Seni Batik, Diklat, Seni Rupa FKSS Padang. 